\title{
Determinants of Effective Budget Utilization in Ethiopian Public Institutions
}

\author{
Zewdu Eskezia Gelaye (MSc) ${ }^{1} \quad$ Birhanu Daba Chali (MSc) ${ }^{2}$ \\ 1.Lecturer, College of Business \& Economics, Department of Accounting \& Finance, Dembi dollo University, \\ Dembi dollo, Ethiopia \\ 2.Head, College of Business \& Economics, Department of Accounting \& Finance, Dembi dollo University, \\ Dembi dollo, Ethiopia
}

\begin{abstract}
According to many scholars finding Budget utilization is affected with intrinsic and extrinsic factors within the boundary of in and outside of the organization having the influence on the proper utilization of the budget. The major objective of this study is to determine the major factors that affect effective budget utilization in Ethiopian public institutions, which is both institutional intrinsic and outside of the institution external factors. To achieve this objective a systematic review of meta-analysis method was used. The the major findings of the review shows that lack of effective monitoring and evaluation, structural problems, employees competency and centralized budget allocation have a significant critical factors which is found in all institutions as a negative determinant factor of in effective budget utilization in Ethiopian public institutions. Based on the findings the researcher recommends that every public institution should give attention regarding with the listed out factors before approval of annual budgets in order to effectively utilize the approved budgets.
\end{abstract}

Keywords: Utilization, Budget, Approval, Centralized, Competency

DOI: $10.7176 /$ RJFA/12-17-02

Publication date:September $30^{\text {th }} 2021$

\section{Background of the Study}

Effective and efficient budget utilization is determinant of socio-economic development of any given country including Ethiopia. In Ethiopia, resources like capital and recurrent budgets are major forms of financial planning in all regions. Most governmental policies that have the potential to make a difference to people's lives cannot to do so without a budget, so that a difficult aggregate expenditure control is highly required to assure an efficient use of resources in accordance with the government priorities(Allen \& Tommasi 2001).

Budget has multiple functions such as: control of public resources, planning for the future, allocation of resources and management of resources. However, the relative strength of each function depends on the current view of the function of budgeting and budgeting tools and techniques, but also depends on the strength of particularorganizations and/or institutional arrangements to support these functions (World Bank, 1998)

The public budget planning is a process by which government sets the level of expenditure, collects revenues and allocates the spending of resources among all sectors to meet national goals (Shah, 2008). Budget implementation on the other hand is the actual execution of the budget and application of funds to the planned activities. During the fiscal year, however, not all allocated budgets are used as per the proposed plan. These could be cases where the approved funds may not be enough to fully accomplish the intended goal. In other instances, the amount allocated to a project may be more than what the project can consume. The disparities between the budget allocated and actual expenditure arise due to multiplicity of factors and improper costing of county functions (Rotich \& Ngahu, 2015). The budget cycle needs to be tracked and at every stage the factors that could be affecting the utilization of the budget analyzed.

In the Ethiopia public sector, the budget implementation period or the financial years run from 1st July to 31 st June. During this period, a lay down medium term expenditure framework budget cycle is followed in the preparation and implementation of the national budget. Budget implementation is the real execution of the budget and application of funds to the planned activities. During the financial year, however, not all funds are expended as per the plan. According to many scholars finding Budget utilization is affected with intrinsic and extrinsic factors within the boundary of in and outside of the organization having the influence on the proper utilization of the budget. Hence, this review of article attempts to assess factors affecting effective budget utilization in Ethiopian public sector desired to prove the problems in one study are the same problem for the other study area and vise verse.

\subsection{Objective of the study}

1.2.1 Major Objective of the Study

The major objective of this study is to determine the major factors that affect effective budget utilization in Ethiopian public institutions. 


\subsubsection{Specific objectives}

1. To determine the effect of organizational intrinsic factors that determines effective utilization of public budgets

2. To determine organization external factors that affect effective utilization of public budgets

\subsection{Review of Related Literatures \\ Overview of Budget}

A budget is defined as an itemized summary of estimated expenditures for a given period along with proposals for financing them (Daniel, 2005). In the public service the main sources of finances include taxes levied directly or indirectly, fines and penalties, revenues from profit making state corporations, charges and fees on services rendered foreign aid and donations from development partners and internal and external borrowing. The monies raised are then applied in main government expenditure sectors such as the regional governments and the zonal sectors which further divide to the zonal offices and Woredas level offices for implementation. These are the points where budgets are to be utilized finally being affected by different level factors. Generally, budget is a vital role to improve the coordination among the various units of the organization. So the organization overall performance depends on the budget with respect to financial plan for implementing the various decision.

\section{Budget Utilization}

Right after the approval of budget prepared by the legislature, the government embarks on the challenging task of spending funds. Utilizing public funds effectively to meet stated policy objectives while ensuring value for money is often just as challenging than planning how to spend it. Several reviews of Public Financial Management performance in developing countries show that countries score significantly better on budget preparation than on budget utilizing. Budget utilization is the phase where resources are used to implement policies incorporated in the budget. As they argued, it is possible to utilize badly a well-prepared budget; it is not possible to utilize well a badly prepared budget.(Schiavo-Campo, 1999)

\section{Concepts Of Under and Over Utilization of Budget}

Over utilizations are sometimes caused by non-compliance of budget managers with the spending limits defined in the budget, when committing expenditures. Since cash allocated to spending units for appropriated expenditures is generally controlled, these overruns generate spending arrears. Overruns are often the result of off-budget spending mechanisms (payment from special accounts, etc. In some countries, payments made through exceptional procedures are not controlled against the appropriations and are therefore an important cause of overruns; lack of compliance can be addressed through strengthening the audit system, and reporting system, and ensuring the effectiveness of the basic budget execution controls. Moreover, overruns can be caused by deficiencies in budget preparation (Allen \& Tommasi, 2001).

Sound budget preparation processes and adequate institutional arrangements are a prerequisite for avoid in govern runs. On the other hand Ketema (2015) expressed that in a number of countries, the official budget is under spent, particularly its non-wages expenditure items. This does not necessarily mean that there is good fiscal discipline in these countries. In some countries with poor governance, under spending of the official budget may coexist with large amounts of budget spending. In most cases, underutilization as well as over utilization is related to insufficiencies in budget preparation and program preparation.

\section{Reason for Variations between Budgeted and Actual Expenditure}

There are a number of factors that can explain why actual expenditure deviates from the levels approved at the beginning of the financial year in any Sector. The reasons for deviations may vary over time. Some of the more common causes are: Deviation in aggregate expenditure; reallocation of fund during budget implementation; policy changes during the year; an inability to implement policies, program and projects; and a lack of financial discipline contribute for variation in budgeted and actual expenditure (Ketema, M. 2006). 


\section{Conceptual framework}

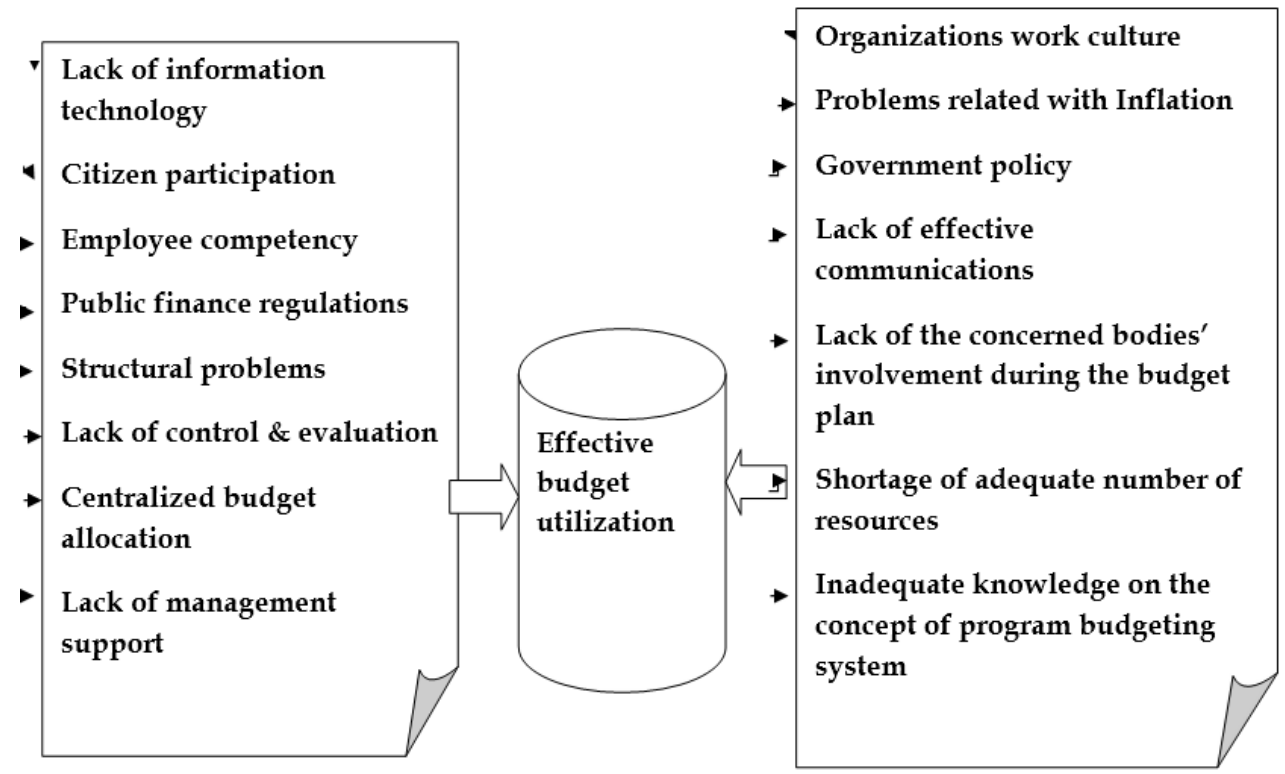

Figure 1: conceptual framework of the study: developed by the researcher

\section{Methodology}

The researcher used qualitative research approach. There are three research approaches. The quantitative approach provides an objective measure of reality, on the other hand, the qualitative approach allows the researcher to explore and better understand the complexity of a phenomenon. Both quantitative and qualitative research approaches may have their own strengths and limitations. According to Sale et al, (2012)

\subsection{Type and Sources Data}

This study used secondary data and the data was obtained from a review of relevant documents and articles.

\subsection{Document Review}

The documents were reviewed by referring most recent information from authorized documents and different reports. Annual reports, legislations, directives and other documents related to the adoption and importance of IFRS were used. The document reviews were used to triangulate the data collected by the questionnaires and interviews.

\subsection{Application of Meta-Analysis}

Meta-analysis aims to combine information across separate but similar studies. Most meta analyses are based on one of two statistical models, the fixed-effect model or the random-effects model. Under the fixed-effect model it assumes that there is one true effect size that the true effect could vary from study to study.

\subsection{Qualitative Meta analysis}

Meta-Analyses are used to pool the results of individual studies. Findings from various individual studies are analyzed statistically by strict procedures. It is an intentional and coherent approach to analyz data across qualitative studies. It is a process that enables researchers to identify a specific research question and then search for, select, appraise, summarize, and combine qualitative evidence to address the research question. It is interpretive analytical technique that uses the qualitative findings reported in previous studies as building blocks for gaining a deeper understanding of particular phenomena. The following articles were major sources of the review 
Summary of reviewed literatures

\begin{tabular}{|c|c|c|c|c|c|}
\hline No & Author & Title & Year & Method & Major findings \\
\hline 1 & $\begin{array}{l}\text { hashim tune } \\
\text { sado }\end{array}$ & $\begin{array}{l}\text { an assessment of } \\
\text { factors affecting } \\
\text { budget utilization } \\
\text { (case of east } \\
\text { wollegaadministrative } \\
\text { zone) }\end{array}$ & 2019 & Descriptive & $\begin{array}{l}\text { inflation, tax compliance, government } \\
\text { policy and structural factors. }\end{array}$ \\
\hline 2 & $\begin{array}{l}\text { Reddy ch } \mathrm{V} \\
\text { Krishna } \& \\
\text { shaiku shahida } \\
\text { sahib }\end{array}$ & $\begin{array}{l}\text { Factors affecting on } \\
\text { budget } \quad \text { utilization } \\
\text { bahirdar r city } \\
\text { administration, health } \\
\text { department, Ethiopia }\end{array}$ & 2020 & $\begin{array}{l}\text { Ordinal } \\
\text { logistic } \\
\text { regression }\end{array}$ & $\begin{array}{l}\text { Management support, organizational } \\
\text { work culture, employee's related factor } \\
\text { and monitoring \& evaluation } \\
\text { significantly affects the budget } \\
\text { utilization }\end{array}$ \\
\hline 3 & $\begin{array}{ll}\text { Dejene } & \text { Tafa } \\
\text { Semeneh } & \\
\text { Bessie } & \end{array}$ & $\begin{array}{l}\text { Intrinsic } \quad \text { Factors } \\
\text { Affecting Budget } \\
\text { Utilization in } \\
\text { Ethiopian Public } \\
\text { Universities }\end{array}$ & 2016 & descriptive & $\begin{array}{l}\text { lack of proper planning, allocation of } \\
\text { budget, Inadequate timely revision of } \\
\text { initial budget, inadequate knowledge, } \\
\text { shortage of } \\
\text { adequate number of human resources } \\
\text { and insufficient involvement of } \\
\text { allconcerned bodies during the budget } \\
\text { plan preparation } \\
\text { Decentralized budget administration } \\
\text { system, absence of result oriented } \\
\text { evaluation of budget performance and } \\
\text { regular revision of plan in accordance } \\
\text { with the available budget, lack of } \\
\text { effective communication, lack of } \\
\text { effective budget monitoring and } \\
\text { evaluation, and } \\
\text { absence of full involvement of the line } \\
\text { managers in planning process were } \\
\text { identified as the most important internal } \\
\text { factors that affected budget utilization in } \\
\text { public universities }\end{array}$ \\
\hline 4 & $\begin{array}{l}\text { mesfin } \\
\text { mahtemeselase } \\
\text { alula }\end{array}$ & $\begin{array}{l}\text { factors affecting } \\
\text { effective management } \\
\text { of public } \\
\text { budget of ethiopia } \\
\text { (case of oromia } \\
\text { regional government- } \\
\text { org) }\end{array}$ & 2019 & descriptive & $\begin{array}{l}\text { citizen participation, employee } \\
\text { competency and public finance } \\
\text { regulations have positive relationship } \\
\text { with the } \\
\text { dependent variable. }\end{array}$ \\
\hline 5 & $\begin{array}{l}\text { Minilik Wube, } \\
\text { Dereje Ademe, } \\
\text { Mulatu Takele, } \\
\text { Ayana Zewdie }\end{array}$ & $\begin{array}{l}\text { Assessment of budget } \\
\text { utilisation (Channel } \\
\text { One) } \\
\text { in the Water Sector } \\
\text { A case study of four } \\
\text { selected woredas } \\
\text { in Benishangul- } \\
\text { Gumuz regional state }\end{array}$ & 2009 & $\begin{array}{l}\text { Descriptive } \\
\& \quad \text { time } \\
\text { series }\end{array}$ & $\begin{array}{l}\text { Low budget allocated to } \\
\text { water compared } \\
\text { discrepancy between the poverty } \\
\text { reduction policy priorities and annual } \\
\text { budget sectoral priorities. } \\
\text { underspending of the budget in the } \\
\text { study woredas. } \\
\text { The growth trend of the budget in } \\
\text { individual districts is inconsistent, } \\
\text { lack of coordination and structural } \\
\text { clarity in the water sector, lack of } \\
\text { consistent and well organised data, } \\
\text { delays in financial disbursements, lack } \\
\text { of effective and } \\
\text { systematic monitoring and evaluation, } \\
\text { and prevalence of centralised budget } \\
\text { allocation at woreda } \\
\text { level. }\end{array}$ \\
\hline
\end{tabular}




\section{Conclusions and Recommendations \\ 4.1 Conclusions}

The major objective of this study is to identify the determinants of effective budget utilization in Ethiopian public institutions. After reviewing the previous researchers' results, the researcher concludes the following.

From all, lack of effective monitoring and evaluation, structural problems, employees competency, centralized budget allocation have been found critical factors that determine effective budget utilization in Ethiopian public universities, Oromia regional government administration and Beninshangul Gumuz water supply.

As we know if there is no systematic and a day today follow up or monitoring everything will be misstated. For every activity of our lives there is a need of monitoring and follow ups. After doing so, at the end, the performance should be evaluated against the plans, to ascertain whether the plans are achieved or not. If there is a negative variance between the budgeted one and the used, then effective measures should be taken and the causes of variance should be Identified and reduced or if possible eliminated. The other variable which is found as a determinant factor in more than two public institutions in Ethiopia is employee's competency. If the employee responsible for the budget is not competent then the allocated budget for each activity will not be correct and enough or it will be in a wrong manor. The third variable that is found to be a determinant factor of Ethiopian public institutions of Beninshangul Gumuz water supply, Ethiopian public universities and Bahir dar city health department, is structural problem. If there is no a clear hierarchy of budgets administration, smooth and facilitating structural relationship between different departments in the organization associated with budget use and continues and transparent information flow among the organizational elements related to budget utilization there will be ineffective utilization of budgets in Ethiopian public institutions.

Other variables which are found determinants of effective budget utilization in Ethiopian different public institutions are the following. inflation, tax compliance, government policy, management support, organizational work culture, employee's related factor, lack of proper planning, allocation of budget, Inadequate timely revision of initial budget, inadequate knowledge, shortage of adequate number of human resources and insufficient involvement of all concerned bodies during the budget plan preparation, absence of result oriented evaluation of budget performance and regular revision of plan in accordance with the available budget, lack of effective communication, and absence of full involvement of the line managers in planning process, Low budget allocated to the institutions relative with the activities, discrepancy between the poverty reduction policy priorities and annual budget sectoral priorities, underspending of the Channel One water budget in the study woredas, inconsistent in the growth trend of the budget, problems with a lack of coordination, lack of consistent and well organised data, delays in financial disbursements.

\subsection{Recommendations}

Based on the findings the researcher recommends that every public institution should give attention regarding with specially the monitoring, control and evaluation functions regarding with the budget, organizational structure, employees competency, employees knowledge and skill, centralized budget allocation and inflation critically and most importantly all that have been found here on the conclusion determinants of effective budget utilization should be considered before any budget approval and usage in any public institution of Ethiopia.

\section{References}

Allen, R. \& Tommasi, D. (eds) (2001) multi-year budgeting and investment programming:

Allen, R. \& Tommasi, D., (2001). Multi-Year Budgeting and Investment Programming. Managing Government Expenditure: A Reference Book for Transition Countries. Paris: OECD SIGMA.

Dejene Tafa \& Semeneh Bessie, (2016) Intrinsic Factors Affecting Budget Utilization in Ethiopian Public Universities: Journal of Economics and Sustainable Development, Vol.7, No.7, 2016

Hashim Tune Sado (2019) An Assessment of Factors Affecting Budget Utilization (Case of East Wollega Administrative Zone): Research Journal of Finance and Accounting, Vol.10, No.19, 2019

Ketema M, (2015) assessment of budget preparation and utilization: the case of Addis Ababa health bureau working paper.

Mesfin Mahtemeselase Alula, (2019) Factors Affecting Effective Management Of Public Budget Of Ethiopia (Case Of Oromia Regional Government-Org: unpublished Masters dissertation

Minilik Wube et al., (2009) Assessment of budget utilisation (Channel One) in the Water Sector: A case study of four selected woredas in Benishangul-Gumuz regional state, Research-inspired Policy and Practice Learning in Ethiopia and the Nile region

Reddy Ch V Krishna \& shaiku shehida sahib, (2020) factors affecting on budget utilization in Bahir dar city health department, Ethiopia: journal of public policy and administration; Vol.9, No.8, 2019

Rotich, C. K. (2015). Factors affecting budget utilization Kericho county government in Kenya. International Journal of Economics, Commerce and Management, 26,27. 
Sale, et al., (2002) Revisiting the Quantitative-Qualitative Debate: Implications for Mixed Methods Research, Quality \& Quantity 36(1)

Schiavo-Campo, S. \&. (1999). Managing Government Expenditure. Asian Development Bank. 